УДК 37.01

\title{
ОСОБЕННОСТИ ПРИМЕНЕНИЯ ТЕХНОЛОГИИ «ДЕБАТЫ» НА УРОКАХ И ВО ВНЕУРОЧНОЙ ДЕЯТЕЛЬНОСТИ
}

\author{
В. В. Ляшенко, О.А. Крутских \\ Средняя общеобразовательная школа № 20, г. Воронеж, Россия \\ Воронежский государственный педагогический университет, Россия
}

Поступила в редакиию 27 мая 2019 г.

\begin{abstract}
Аннотация: В статье рассматриваются особенности проведения школьного турнира игры «Дебаты», значимость применения данной технологии для развития и самореализации учеников старших классов. Приводятся примеры тем с применением географических знаний.
\end{abstract}

Ключевые слова: внеурочная деятельность, дебаты, турнир, развитие личностных качеств, самореализация.

\section{Features of technology application «Debate» in lessons and in extraction activities}

\section{V. Lyashenko, O. A. Krutskikh}

Abstract: The article discusses the features of the school tournament of the game «Debate», the significance of the use of this technology for the development and self-realization of high school students. Examples of themes with the use of geographical knowledge are given.

Key words: extracurricular activities, debates, tournament, development of personal qualities, selfrealization.

\section{ВВЕДЕНИЕ}

Практически каждый день, независимо от местонахождения: дома, на работе, в школе, в других общественных местах, мы сталкиваемся с ситуациями, когда нам приходится отстаивать свою точку зрения. Нередко от умения убедить оппонента напрямую зависит карьерный рост и успех многих начинаний. Для страны одной из приоритетных задач выступает воспитание уверенных в себе, эрудированных, высококультурных и целеустремленных граждан. Особенно важно, чтобы молодое поколение не потерялось и правильно сориентировалось в потоке получаемой со всех сторон информации. Подросткам необходимо приобретать навыки свободного обмена собственным мнением по любой проблеме, доказывать его достойно и аргументировано.

Системно-деятельный подход, который основан на личностно-ориентированных развивающих

() Ляшенко В.В., Крутских О.А., 2019

Материал статьи доступен по лицензии Creative Commons "Attribution" 4.0 технологиях обучения, считается более эффективным по сравнению с вербальным способом передачи знаний. Прием «Дебаты» является одним из примеров применения данного подхода в современной образовательной среде [2].

Отличительной чертой приема «Дебаты» является способность к развитию активности обучающихся, в том числе и творческой, анализ любого предмета диалога с различных точек зрения. Благодаря «Дебатам» появляется возможность формирования у подростка ораторского мастерства и лидерских качеств. Участвуя в дебатах, подростки также приобретают навыки толерантного диалога и поведения - признавать право на существование других взглядов при отстаивании собственной позиции, используя метод бесконфликтного решения проблем.

По-сути прием проведения занятия в виде «дебатов» представляет собой игру - ролевую игру. Каждый из участников продумывает свою роль, но при принятии решений они не всегда могут знать, какие доводы будет предлагать команда соперни- 
ков и поэтому для игроков требуется быстрая реакция, поиск эффективных способов решения проблемы, для того чтобы показать свои умения «здесь и сейчас».

Данная форма проведения занятия позволяет реализовывать в соответствие с требованиями Федерального государственного общеобразовательного стандарта основного общего образования личностные, метапредметные и предметные результаты обучения [4]. Поэтому, дебаты представляют собой интерактивную инновационную образовательную технологию, которая направлена на развитие обучающегося, реализацию его потенциальных возможностей, формирование его мировоззрения для восприятия окружающего мира и жизни в нем.

\section{МЕТОДИКА}

Дебаты начинаются с темы. Тема представляет собой довольно спорное суждение, которое формирует необходимую основу для споров - дебатов. Обязательно тема должна быть сформулирована как утверждение, например: «Глобальное потепление угрожает Земле». Любая тема, выносимая на дебаты, должна соответствовать нескольким критериям, к которым относятся: конкретность формулировки; однозначность понимания; перспективность для обсуждения и значимость для учащихся.

В методической литературе описаны варианты разных форматов дебатов, но для обучающихся наиболее оптимально подходит Всемирный формат школьных дебатов. В его основу положена имитация классических парламентских прений с «правительством» и «оппозицией».

Для игры выбирается две команды по три спикера. Одна команда выполняет роль «утверждения» (правительство) и она обязана давать положительные доводы по предложенной теме. Другая команда выполняет роль «отрицания» или оппозиции и выстраивает свою стратегию, доказывая, что тема неверна. Каждого представителя команды называют по их порядковому номеру выступления. Например, «третий спикер утверждения» или «первый спикер отрицания».

После определения темы игры, каждая команда вырабатывает в поддержку собственной позиции (утверждения или отрицания) по три существенных аргумента. Затем продумывают опровержения возможных аргументов оппонентов. Смысл данной работы - найти такие доказательства своей позиции, которые отвечали бы на вопрос поче- му Ваша команда права и почему Ваши оппоненты неправы. Для успешного дебатирования глубина продуманных командой аргументов нередко имеет решающее значение.

По правилам игры в ходе выступления спикеры команды могут задавать вопросы оппонентам только во время речей спикеров. Самое главное, чтобы вопрос был уточняющим, кратким, проясняющим или атакующим. Спикер, который выступает, может не принимать во внимание все информационные вопросы, но в тоже время, если он не примет ни одного вопроса, то это будет неудовлетворительно оценено судьями. В среднем, каждый спикер может принять по два-три вопроса во время свой речи. В данном формате дебатов существует правило: «Два задать, два принять». Каждый выступающий спикер вправе сам распоряжаться своим временем. Он может принимать и отклонять вопросы, а также может попросить задающего подождать некоторое время для завершения собственной речи.

В общем виде структурировать выступления спикеров «Утверждения» и «Отрицания» можно следующим образом. Первые спикеры в основном представляют позицию команды, интерпретируя и объясняя тему в своем понимании. Вводят и разделяют аргументы. Вторые спикеры две трети своей речи строят на опровержении аргументов оппонентов, не забывая об основной линии своей команды и аргументах, выдвинутых в поддержку своей позиции. Третьи спикеры также в основном опровергают ранее услышанное и восстанавливают исходный кейс своей команды, но вводить новые аргументы уже не имеют права.

Спикеры противоположных команд выступают по очереди, без перерывов на обсуждение, команда Утверждения начинает и заканчивает игру.

В итоге спикеры обеих команд произносят 6 речей, продолжительностью от 3 до 8 минут, и в заключительной речи от 1 до 4 мин. Продолжительность выступления лучше заранее оговорить с командами, при этом учитывать время, выделенное на игру и глубину проработки темы участниками дебатов. Все спикеры, кроме начинающего дебаты, обязаны опровергать аргументы противоположной команды. Первые и вторые спикеры команд также вводят самостоятельные аргументы в поддержку позиции команды. Третьи спикеры строят свою речь на опровержении, заключительная речь направлена на подведение итогов.

Дебатами управляет судья. В данной игре ничьей не существует. Обязательно должен быть ре- 
зультат - победа одной команды и поражение другой. Вердикт принимает и выносит судья, который внимательно наблюдает за дебатами. Каждый судья должен иметь ясное представление о том, что такое хорошее и плохое дебатирование, случайные или произвольные решения не имеют права на существование.

Критерии судейства можно выделить следующие.

1. Стиль. Здесь понимается ораторское искусство спикера, его способ выступления и манера говорить, стиль поведения, юмор, искренность, доброжелательная уверенность в своей позиции.

2. Содержание речи спикера, сила представленных аргументов, умение их правильно представить и раскрыть.

3. Стратегия, выдерживание общей линии команды, структура выступлений $[1,3]$.

Таким образом, судья оценивает: какую информацию и каким способом спикер донес до аудитории.

\section{РЕЗУЛЬТАТЫ ЭКСПЕРИМЕНТА}

Дебаты проводятся во внеурочное время и на уроках, допустим, при закреплении пройденного материала, как один из приемов интерактивного обучения.

В нашей школе мы проводим ежегодный турнир «Дебаты» в рамках декады истории и географии. Турнир состоит из нескольких этапов: 1) отборочный этап - игра между командами одного класса; 2) полуфинал - играют команды классов в параллели; 3 ) финал - играют команды-победители полуфиналов.

Между всеми играми необходим перерыв от трех до пяти дней, чтобы команды глубже проработали тему, подобрали необходимые аргументы и факты, а, следовательно, провели захватывающие и интересные дебаты.

Темы для дебатов могут быть сформулированы в разных направлениях. Они касаются как предметных областей знаний, так и межпредметных, связанных с экономикой, культурой, политикой, или те, которые интересуют подростков на данном этапе их жизненного пути. В качестве примера можно привести несколько тем, которые относятся к предметной области географии: «На Земле наступает глобальное потепление»; «Гастарбайтеры необходимы России»; «Гигантская территория России тормозит ее экономическое развитие»; «Развивающиеся страны нуждаются в сильной диктатуре» и другие.
Опыт проведения дебатов в МБОУ СОШ № 20 города Воронежа показал, что при выборе темы необходимо обращать внимание на несколько основных моментов. Для первых туров турнира темы можно брать в рамках предметного материала, а на финальную игру участники часто предлагают собственные темы, которые интересны для них.

Чтобы организовать школьный турнир по дебатам, нужно заинтересовать администрацию школы, а не только учеников и учителей-предметников. Чтобы учителя судейской лиги и «болельщики» команд-участниц смогли присутствовать на игре, возникает необходимость корректировки расписания, ведь турнир проходит в течение нескольких недель и собирает разновозрастных участников. Но главная сложность дебатов как формы обучения заключается в огромной предварительной работе учителя. Необходимо предварительно познакомить участников с сущностью игры, системой подбора аргументов, распределить роли, учитывая интеллект и темперамент будущих спикеров.

На этапе подготовки для команд-новичков особенно велика роль учителя как наставника и помощника. Сложности возникают у восьмиклассников, которые в силу возраста и недостатка знаний еще не вполне проявляют широту и глубину суждений по вопросам общественной и гражданской жизни. Можно, а иногда и нужно, привлекать наставниками выпускников 11-х классов, прошедших трехлетнюю «школу дебатов».

Тренеру следует набраться терпения, так как часто приходится сталкиваться с отсутствием навыков анализа, обобщения и сравнения у подростков, низким уровнем развития речи, неумением выделять главное, существенное. По многолетним наблюдениям, интерес к участию в турнире у ребят резко поднимается после присутствия на игре более опытной команды. Поэтому на финальные игры турнира мы обязательно приглашаем учеников среднего звена.

Участвуя в дебатах, подростки раскрываются в условиях командного взаимодействия, здесь необходимо соблюдать корректность в поведении спикеров, вовремя «гасить» любые проявления агрессии, приветствовать юмор и доброжелательность участников. И тогда, дебаты выступят как эффективное средство формирования личностно значимой позиции школьников.

Итог игры предсказать невозможно. Часто бывает, что более слабая команда в результате выглядит значительно убедительнее опытных и знающих соперников. Немаловажную роль для победы 
в игре играет уверенность спикеров в правильности своей позиции, эмоциональность, интересные вопросы, юмор и находчивость - так называемая «харизма» участника.

Подводя итог, хочется сказать, что участие школьников в турнирах разного уровня дает им уверенность в своих силах, повышает самооценку и способствует развитию метапредметных результатов обучения и дальнейшему определению жизненного пути.

\section{СПИСОК ЛИТЕРАТУРЫ}

1. Всемирный формат школьных дебатов. - URL: http://ru.wikipedia.org/wiki/Всемирный_формат_школьных_дебатов

2. Калинкина Е. Г. Дебаты на уроках : учебно-методическое пособие для учителя / Е. Г. Калинкина. - Москва : Бонфи, 2001.

3. Международная образовательная ассоциация «Дебаты» (IDEA). - URL:http://ru.wikipedia.org/wiki/

Ляшенко Валентина Владимировна

учитель географии МБОУ СОШ №20, г. Воронеж, E-mail: 1-valentina-22@ yandex.ru

Крутских Ольга Александровна

кандидат географических наук, заведующий кафедрой географии и туризма, Воронежского государственного педагогического университета, E-mail: olj.kru@yandex.ru
Международная_образовательная_ассоциация_"Дебаты" + http://www.idebate.org/.

4. Светенко Т. В. Путеводитель по дебатам : учебное пособие для педагогов и учащихся / Т. В. Светенко. - Москва : Бонфи, 2001.

\section{REFERENCES}

1. Vsemirnyy format shkol'nykh debatov [Worldwide format for school debate]. Available at: http:// ru.wikipedia.org/wiki/Vsemirnyy_format_shkol'nykh_debatov

2. Kalinkina E. G., Debaty na urokakh: uchebno-metodicheskoe posobie dlya uchitelya [Debate in the classroom: a teaching aid for the teacher]. Moscow, Bonfi, 2001.

3. Mezhdunarodnaya obrazovatel'naya assotsiatsiya «Debaty» (IDEA) [International Educational Association «Debate» (IDEA)]. Available at: http://ru.wikipedia.org/ wiki/Mezhdunarodnaya_obrazovatel'naya_assotsiatsiya_ "Debaty" + http://www.idebate.org/.

4. Svetenko T. V., Putevoditel' po debatam: uchebnoe posobie dlya pedagogov $i$ uchashchikhsya [Debate Guide: A Study Guide for Educators and Students]. Moscow, Bonfi, 2001.

Lyashenko Valentina Vladimirovna

Teacher of geography at school № 20, Voronezh, E-mail: 1-valentina-22@yandex.ru

Krutskikh Olga Alexandrovna

Candidate of Geographical Sciences, Head of the Department of Geography and Tourism, Voronezh State Pedagogical University, E-mail: olj.kru@yandex.ru 